\title{
Encyclopedia of Case Study Research
}

\author{
A. Mills \\ G. Durepos \\ E. Wiebe \\ Michael P. Pagano \\ Fairfield University, mpagano@fairfield.edu
}

Follow this and additional works at: https://digitalcommons.fairfield.edu/communications-books Copyright 2010 Sage

Content archived here with permission from the copyright holder.

\section{Recommended Citation}

Mills, A.; Durepos, G.; Wiebe, E.; and Pagano, Michael P., "Encyclopedia of Case Study Research" (2010). Communication Faculty Book Gallery. 8.

https://digitalcommons.fairfield.edu/communications-books/8

This item has been accepted for inclusion in DigitalCommons@Fairfield by an authorized administrator of DigitalCommons@Fairfield. It is brought to you by DigitalCommons@Fairfield with permission from the rightsholder(s) and is protected by copyright and/or related rights. You are free to use this item in any way that is permitted by the copyright and related rights legislation that applies to your use. For other uses, you need to obtain permission from the rights-holder(s) directly, unless additional rights are indicated by a Creative Commons license in the record and/or on the work itself. For more information, please contact digitalcommons@fairfield.edu. 


\section{H}

\section{Healthcare Practice GUIDELINES}

Healthcare practice guidelines, also referred to as clinical practice guidelines, are intended to help standardize treatment decisions and patient care. These guidelines are used throughout the Western world and intended to serve as algorithms for healthcare providers to use in evaluating patients, determining treatment options, and providing care. The clinical practice guidelines are developed based on clinical research, data gathering, and objective analyses. Healthcare providers worldwide are encouraged to use the thousands of different guidelines to promote a more consistent approach to patient care and decision making. Case studies are frequently used to assess the implementation and effectiveness of healthcare practice guidelines.

\section{Conceptual Overview and Discussion}

Historically, in the Western world, healthcare practice was an individual skill learned at an accredited school of medicine, nursing, etcetera. Providers were educated, examined, and licensed and then expected to apply their knowledge and skills independently to the assessment and treatment of patients' illnesses or injuries. However, in an effort to codify and normalize the treatment and decision-making process, healthcare practice guidelines began to be developed in the latter half of the 20th century.
The concept for creating clinical practice guidelines derives from the need to disseminate the latest clinical information to healthcare providers and improve the quality of care by:

- Standardizing treatment decisions

- Delivering the best outcomes possible

- Maximizing patient safety

- Enhancing cost effectiveness

To accomplish these goals, healthcare practice guidelines rely on analyses of published case studies and other data as the sources for evidencebased medicine. The theory of evidence-based medicine was first postulated by researchers from McMaster's University in the early 1990s. Evidencebased medicine evolved from an effort to refocus clinical decision making and treatment from a subjective undertaking by individual providers to a standardized practice based on published research, clinical data, and technological advances. By utilizing a combination of widely accepted experiential and clinical research evidence related to diseases, injuries, and treatments, healthcare practice guidelines were developed for a wide variety of diagnoses and conditions.

Over the past three decades the creation of healthcare practice guidelines has exploded. According to the U.S. Agency for Healthcare Research and Quality (AHRQ) Web site, in 2008 there were more than 2,300 different healthcare practice guidelines. These guidelines describe the 
diagnosis, treatment, and care for patients with diseases ranging from hypertension to malignant bone cancer and from chest trauma to acute cardiovascular accidents. However, the complexity and diversity of the vast number of guidelines being developed throughout the world does not mitigate the fact that critics remain concerned that the proliferation of guidelines will standardize health practices to such an extent that the quality of care will suffer. In addition, while research has shown that use of healthcare practice guidelines does effectively change some providers' behaviors, decision making, and outcomes-many providers do not adhere to them.

The rejection of healthcare practice guidelines has been explained by George Weisz and others as a reaction to the perception that guidelines resulted from politicians' and administrators' desire to control economic rather than healthcare issues. Furthermore, many providers have argued that the use of healthcare practice guidelines reduces their professional autonomy. However, it has also been postulated that the increasing emphasis on clinical practice guidelines results from the sociological imposition of outside forces, by nonproviders, on healthcare decision making and practice. With these varied concerns impacting acceptance and utilization of healthcare practice guidelines, researchers have suggested using theoretical frameworks to enhance provider adoption.

Using the theory of planned behavior is one approach that has been suggested for increasing the acceptance of healthcare practice guidelines. Behavioral change theory provides a mechanism for guideline developers to identify and assess the issues related to behavior change and guideline adoption, as well as methods for evaluation and implementation. Behavioral change theory has the potential to enhance the implementation and acceptance of healthcare practice guidelines by organizing the various components and incorporating evidencebased medicine evaluations of the guidelines.

\section{Application}

Clinical practice guidelines can be used in countless healthcare settings to provide patients with a standardized level of care based on the latest information from published studies and objective analysis. Similarly, assessments of healthcare practice guidelines provide an ideal opportunity for case study research. From a single case study exploring provider behaviors, decision making, and treatment practices, to comparative case studies examining multiple instances of implemented guidelines and their outcomes, case studies afford researchers an applied approach to assessing guideline development, utilization, and effectiveness.

An example of how a case study approach can be used to inform the development of healthcare practice guidelines can be illustrated vis-à-vis a cancer pain management study. The researchers relied on case studies of cancer patients' pain management to assess the providers' clinical decision making and treatment plans. These case studies included individual interviews with patients, their healthcare providers, and caregivers regarding the patients' pain management and quality of life. The data from the interviews were used in multidisciplinary focus groups of healthcare providers and administrators to evaluate and refine the current pain management policy. Based on the evidence from the case studies, the focus groups developed and disseminated more holistic clinical guidelines for cancer patients' pain control.

\section{Critical Summary}

Healthcare practice guidelines have been used to minimize the variability between providers in the treatment, decision making, and care related to numerous diseases and conditions. This effort toward standardizing healthcare practice relies on case studies, clinical trial research, and publications as the sources for the evidence-based medicine that underlies the development of clinical practice guidelines. Further, with technology and computers, providers have nearly instant access to all types of healthcare practice guidelines and treatment options. However, the drive toward standardization prompted providers' concerns that guidelines were being developed to control and regulate their behaviors for economic- and administrative-, not healthcare-related reasons. Case studies can be used to evaluate the providers' behaviors as well as the outcomes related to use of healthcare practice guidelines.

Michael P. Pagano

See also Comparative Case Study; Sensemaking; Validity 
Further Readings

Ceccato, N., Ferris, L., Manuel, D., \& Grimshaw, J. (2007). Adopting health behavior change theory throughout the clinical practice guideline process. Journal of Continuing Education in the Health Professions, 27(4), 201-207.

Claridge, J., \& Fabian, T. (2005). History and development of evidence-based medicine. World Journal of Surgery, 29, 547-553.

National Guideline Clearinghouse. (2009). Guideline index. AHRQ. Retrieved November 12, 2008, from http://www.guideline.gov/browse/guideline_index.aspx

Riba, A. (2008). Evidence-based performance and quality improvement in the acute cardiac care setting. Critical Care Clinics, 24, 201-229.

Weisz, G., Cambrosio, A., Keating, P., Knaapen, L., Schlich, T., \& Tournay, V. (2007). The emergence of clinical practice guidelines. Milbank Quarterly, 85(4), 691-727. 